\title{
CULTURA LAICA Y DEMOCRACIA
}

Laura Baca*

Colocar el movimiento de las ideas y el movimiento de las decisiones políticas en niveles diferentes significa moverse en la doble dirección de desconocer tanto la subordinación de la cultura a la política, cuanto la subordinación de la política a un sistema de ideas impuesto como guía a la acción, lo primero representa el principio de la politización integral de la vida del hombre, en el cual consiste el presupuesto de cualquier tentación totalitaria, mientrás que lo segundo ha siempre alimentado el viejo mito del rey-filósofo lo que presupone la posesión absoluta de la verdad por parte de individuos privilegiados.

Norberto Bobbio ${ }^{1}$

\section{Espacios de la cultura: el pluralismo}

La democracia necesita un determinado tipo de cultura capaz de relacionarse con los valores y los ideales que persigue dicha forma de gobierno, pero también y al mismo tiempo, tal cultura debe aprender a convivir y dar sustento a este orden

* Universidad Autónoma Metropolitana.

${ }^{1}$ Norberto Bobbio, "Cultura laica: una terza cultura?", en Cattolici, laici, marxisti attraverso la crisi, 1978, Turín, Stampatori, p. 33. 


\section{LAURA BACA}

político fundado en el pluralismo. Hablar de cultura laica y democracia nos remite a un importante binomio que es característico de las sociedades contemporáneas. Recordemos que la democracia representa una forma de gobierno que se lleva a cabo a través de específicas "reglas del juego" y que considera la participación de los distintos grupos con miras a alcanzar determinados fines, como es el bien común, dentro de un marco de tolerancia entre las diferentes interpretaciones. Es en este sentido que cultura laica y democracia se relacionan y por lo tanto puede decirse que ambas resultan complementarias, es decir, tanto la cultura laica necesita de la democracia para poder subsistir, como la democracia requiere de las distintas expresiones de la cultura para elaborar la diferencia que produce el pluralismo. La cultura laica representa, en este sentido, un ámbito regulativo de posiciones divergentes que conviven entre sí dentro de un espacio pluralista. Pero no debemos olvidar que, por el otro lado, la cultura laica también representa un "método" eficaz para asegurar la no proliferación de expresiones totalizantes en relación con los propios valores e ideales, lo que coincide con la "parcialidad" de la propia visión de las cosas. ${ }^{2}$ Estos dos ámbitos de la cultura laica tienen su origen histórico dentro del concepto más general de cultura. Tengamos presente que si bien la concepción de cultura ha asumido históricamente diversas definiciones y que por lo tanto ha involucrado diversos valores, la acepción clásica, por su parte, nos remite al proceso de educación y desarrollo del ser humano en todas sus "funciones psicofísicas", formando parte del proceso de civilización, ya que permite que el ser humano se encuentre involucrado en un contexto social en el cual se exaltan, entre otras cosas, las funciones civiles. $^{3}$

Para los griegos el valor contemplativo de la cultura no excluía el compromiso político que encontraba su máxima expresión en la "Polis" como comunidad organizada. Recordemos que los ideales políticos de

${ }^{2}$ Risieri Frondizi, ¿Qué son los valores?, 1995, México, FCE.

${ }^{3}$ Nicola Abbagnano, voz "Cultura", en Diccionario de Filosofia, 1995, México, FCE. 
la democracia en Atenas, igualdad entre los ciudadanos, libertad -más bien colectiva que individual-respeto por la ley y la justicia, han forjado el pensamiento occidental. En el Renacimiento se acentúa la autonomía de las características humanas y se valoriza el compromiso civil, perdiendo de este modo su carácter aristocrático al proponerse como instrumento de educación y liberación de todos los hombres. En este período se plantea la renovación del hombre no sólo en su individualidad sino también en su vida asociada. La.cultura laica durante el Renacimiento se expresó principalmente como un conflicto entre sistemas de valores: el cristiano y el "pagano". En efecto, autores del período, como Maquiavelo, Giordano Bruno y Campanella se niegan a lo que consideran "la verdad única de la cultura cristiana".

Otro antecedente histórico fundamental en el proceso de laicización de la cultura lo encontramos durante la Ilustración. Aquí la cultura laica se oponía a un sistema unitario y orgánico representado por el absolutismo y por lo tanto exalta la idea del progreso en donde el hombre, con el uso de la razón, está preparado para luchar contra los prejuicios tradicionales, erigiéndose en guía de la vida social. Recordemos que la Ilustración encarnó un cambio radical en términos intelectuales destinado a caracterizar en profundidad la historia moderna de Occidente y que consiste sobre todo, en un específico modo de relacionarse con la razón.

Aunque en este contexto histórico es más apropiado hablar de espíritu laico que de cultura laica, al que es posible identificar en su combate contra el clericalismo, el confesionalismo e incluso el ateísmo en cuanto sistema absoluto. En realidad el espíritu laico se opone a las rígidas concepciones del mundo de carácter dogmático, que se caracterizan por la manera sectaria con que tratan de imponer sus ideas. El espíritu laico ha producido una de las más grandes conquistas del mundo moderno: la tolerancia religiosa de la cual emergió la tolerancia de las ideas y por último la tolerancia de las opiniones políticas. ${ }^{4}$ De esta

${ }^{4}$ Sara Sefchovich, "Isaiah Berlin: el zorro", en Los intelectuales y los dilemas politicos en el siglo $X X$, México, FLACSO-TRIANA, p. 311, de próxima aparición. 


\section{LAURA BACA}

forma el espíritu laico ha permeado al conjunto de la sociedad moderna y civil. Le hacen homenaje las cartas de los derechos humanos que constituyen la base irrenunciable de los Estados democráticos. El espíritu laico no es una nueva cultura sino que es más bien la condición para la convivencia de todas las posibles culturas.

Durante el siglo XX encontramos múltiples definiciones acerca de la cultura. A lo largo de este período, se ha preferido utilizar el término cultura laica en relación con el de espíritu laico. Nos interesa resaltar no tanto las concepciones que exasperan los contrastes, sino aquellas perspectivas en las que se reivindica una relativa autonomía para la cultura. Dicho de otra forma, se privilegia una interpretación -no mecánica ni pasiva- que ve en la cultura un proceso con una dinámica propia y que por lo tanto se vincula con las tareas civiles de la sociedad a través de la difusión del saber. De este modo la cultura puede ser entendida como un conjunto de comportamientos individuales que dan vida a las estructuras y a las instituciones sociales dentro de un pluralismo multiforme donde cada uno "cree" en formas diversas e irrepetibles. En este sentido, la pluralidad, la diferencia y la parcialidad "enriquecen nuestra mirada sobre el mundo, nos ofrecen respuestas en

216 sentido múltiple (...) es la acción cotidiana de la cultura".5 De ahí la importancia de que la cultura no sea adjetivada o instrumentalizada por la política.

Desde esta perspectiva la cultura no debe ser entendida como un cuerpo homogéneo sino como pluralidad de formas culturales que se distinguen sobre bases regionales y sociales. Por lo tanto la cultura constituye un patrimonio intelectual y material, heterogéneo pero integrado, duradero y sujeto a continuas transformaciones, con un ritmo variable según la naturaleza de sus elementos y la época histórica. La cultura provoca una realidad con diferentes tonalidades y matices que expresan divergencias en su interior y no puede ser considerada como una estructura inmutable en cada tiempo y lugar, dado que se encuentra en continuo movimiento. Esta concepción de la cultura que pro-

${ }^{5}$ Mario Reale, Le idee della sinistra, 1992, Roma, Riuniti, p. 112. 


\section{CULTURA LAICA Y DEMOCRACIA}

mueve el pluralismo de las perspectivas es la más compatible con la democracia necesaria en los tiempos que corren. ${ }^{6}$

\section{La cultura laica hoy}

En la época contemporánea existe la idea de que la cultura laica se encuentra en una posición intermedia entre aquellas culturas que tratan de monopolizar el saber. Esta herencia valorativa ha sido asumida por la democracia en un grado tal que en estos momentos de profundos cambios culturales, sociales y políticos resulta un ejercicio saludable para la misma democracia la formulación de algunos interrogantes, tales como: ¿qué significa la cultura laica en las sociedades contemporáneas?; ¿qué función ejercita la cultura cuando es concebida como una expresión del pluralismo sobre todo en momentos en que imperan fuertes contradicciones tanto en la política como en la cultura?; y finalmente, ¿puede la cultura laica ser considerada un elemento útil para caracterizar a las modernas democracias? Analizar estos interrogantes en los tiempos que corren nos obliga a una breve revisión terminológica que permita ilustrar su importancia en la construcción de la sociedad democrática. Resulta necesario, en primer lugar, referirnos al análisis de los diferentes espacios de la cultura laica, a los usos que se le han dado, así como a las diferentes simbologías que representa.

Por la complejidad de los problemas es necesario reconocer que aún permanecen muchas temáticas sin solución en el tintero del fin de siglo. Quizá la cuestión más importante hoy sea la discusión en torno al hecho de si es aún vigente pronunciarse a favor de la construcción de una cultura laica o si esto sólo constituye una cuestión de carácter filosófico que no puede ser aplicada a la realidad concreta. En segundo lugar es importante referimos a las dimensiones que encarna el concepto de democracia. Debemos reconocer que en la democracia, la cultura y la política transitan sobre caminos diferentes y que sólo en algunas ocasiones se encuentran.

${ }^{6}$ John Rawls, Liberalismo politico, 1994, Milán, Comunitá, p. 69. 
Sostenemos que en una sociedad libre tanto la cultura como la política deben tener su propia autonomía. Cuando se hace referencia a la distinción entre la esfera de la cultura y la esfera de la política, se resalta la convicción de que para el pensamiento laico la política y cultura no coinciden. Aún y cuando cada forma de cultura pudiera tener un proyecto político, éste siempre tendrá tiempos y modos diferentes de los de un programa estrictamente político que debe resolver los problemas día con día. Recordemos que cuando la cultura adquiere un carácter laico, se opone a uno doctrinal o dogmático, es decir, a la rigidez propia de la ortodoxia. Se ha sostenido que la cultura laica tiene que ver con la diversidad. Es una posición intermedia entre concepciones totalizantes, que se contrapone al monismo de los valores, y por lo tanto a aquellas concepciones que colocan los valores en un orden jerárquico.

Debemos resaltar que las principales características de la cultura laica son: la distinción entre las esferas de la política y la cultura, la autodeterminación, la independencia y el ejercicio de la crítica, la mediación de los conflictos, la no ideologización y la tolerancia. En consecuencia la cultura laica representa una especie de "condición mínima" para la convivencia libre entre subjetividades. ${ }^{7}$ En esta perspectiva, tal tipo de cultura no tiene que ver con la de un sistema cerrado de ideas que contiene principios definidos una vez y para siempre. ${ }^{8}$ El término laico constituye un punto de referencia para la colaboración entre fuerzas colectivas, entre comunes posiciones ideales y tradiciones culturales. En efecto, la cultura laica posee un carácter dinámico que le permite renovarse y modificarse constantemente, producto de la relación entre los distintos sistemas de ideas y valores. Por este motivo no puede ser tomada en consideración como fuerza política. La laicicidad establece un nexo posible entre moral y política, como sistema ético y sistema de poder, que intercambian en una libre comunicación de sig-

${ }^{7}$ Cfr. V.A., "Cultura e impegno", en Micromega, 1996, Roma.

${ }^{8}$ Para analizar en profundidad estas concepciones se recomienda el libro La cultura filosófica italiana, 1982, Nápoles, Guida Editori. 
nificados. Extendiendo la pluralidad de posiciones se puede lograr una libre maduración de la conciencia. La laicicidad expresa sobre todo un método que se cristaliza en el diálogo para tratar de encontrar los puntos de acuerdo y desacuerdo de aquello que distingue a las partes. ${ }^{9}$

\section{III. ¿Cuál democracia para la cultura laica?}

Diversos autores consideran que las instituciones democráticas modernas han sido influenciadas por una amplia gama de factores, entre los cuales se encuentran la tradición republicana, el nacimiento de gobiernos representativos y la igualdad política. De acuerdo con estas tradiciones la existencia de un proceso democrático presupone no sólo un complejo de instituciones sino también un conjunto de derechos y deberes legales. Lo importante es que los ciudadanos se encuentren en condiciones de gobernarse a sí mismos con las reglas y procedimientos que han acordado. Se subraya con insistencia el "principio de igual consideración de los intereses", lo que en otras palabras significa "eliminar las desigualdades de los puntos de partida, eliminando las desigualdades económicas". ${ }^{10}$ En este sentido, la democracia no impide a nadie luchar por la consecución de sus propios fines, "a condición de que, cada uno permita a los demás luchar por los fines que cree mejores y todos se pongan de acuerdo sobre un criterio, el más objetivo posible, para decidir cada vez y periódicamente, jamás definitivamente, cuales son los fines que deben prevalecer". ${ }^{11}$ En esta perspectiva uno de los ideales de la democracia es representada por la renovación

${ }^{9}$ He tratado estos temas en: "Bobbio y la virtud del diálogo democrático", en La Jornada Semanal, núm. 286, 6 de noviembre, 1994 y "Diálogo y Democracia", Cuadernos de divulgación de la cultura democrática, núm. 13, 1996, Instituto Federal Electoral.

${ }^{10}$ Robert Dahl, La Democrazie e i suoi critici, 1992, Roma, Riuniti, p. 36.

${ }^{11}$ Norberto Bobbio, "Il Braccio armato della tirannide", en Le ideologie e il potere in crisi, 1979, Firenze, Le Monnier, p. 115. 


\section{LAURA BACA}

gradual de la sociedad a través de la libre discusión de las ideas. Por lo tanto resulta claro que el problema de la cultura radica en la importancia decisiva del "uso público de la razón" y de la elaboración de presupuestos que permitan sentar las premisas para su propia renovación. Esto significa que el nacimiento de los sistemas políticos pluralistas ha hecho posible la convivencia entre diferentes culturas sin que cada una pierda su autonomía y racionalidad. Recordemos que ninguna concepción política o ideológica puede aspirar a tener el monopolio de la verdad. En una sociedad pluralista, como bien señala Bobbio, los partidos deberían representar intereses económicos-sociales que, aunque contrapuestos, pueden siempre ser objeto de negociación. ${ }^{12}$

La coexistencia de diferentes culturas en una democracia provoca un efecto en dos direcciones: de un lado, la democracia posibilita la expresión de las diferentes expresiones culturales; en tanto que el desarrollo de la cultura laica permite a los ciudadanos adquirir, a través de una adecuada educación, un conocimiento mayor de sus derechos y deberes.

Aunque la democracia corre el riesgo de un cierto grado de incertidumbre en la medida en que se sustenta en una necesaria renovación periódica del consenso, no puede renunciar a tal confrontación porque el pluralismo vive en la dialéctica consenso-disenso. En efecto, la cultura laica vive en la expresión de esta pluralidad y, para decirlo con Max Weber, se expresa en el relativismo de los valores. La cultura se autodetermina siguiendo sus procesos específicos y estableciendo una relación de autonomía relativa respecto de la política. Por lo tanto, ser autónomos significa la libertad de aceptar o de rechazar las propias normas en la medida en que ser independientes implica tener diferentes opciones en el campo de las decisiones políticamente significativas. En las democracias complejas está presente un elevado nivel de autonomía personal de los ciudadanos en las decisiones individuales y colectivas, lo cual es producto, en buena medida, de la cultura laica.

${ }^{12}$ Norberto Bobbio, "Cultura laica: una terza cultura?", en Cattolici, laici, marxisti attraverso la crisi, op. cit., p. 31. 
La coexistencia de diferentes sistemas de valores permite la inclusión del mayor número de ciudadanos en la construcción democrática. En efecto, en las democracias y siguiendo los pasos de Stuart Mill, a la ciudadanía se le atribuye un crecimiento moral y la adquisición de un sentido más maduro de responsabilidad de las propias acciones así como "una mayor propensión a reflexionar acerca de las consecuencias de las propias acciones". ${ }^{13}$ Estas afirmaciones implican la concepción de un ciudadano ilustrado que debe tener adecuadas y equitativas oportunidades para comprender los medios y los fines de la acción política así como sus posibles consecuencias para la democracia.

En consecuencia, con la existencia de una cultura laica se fortalece el comportamiento cívico que refuerza la calidad de la democracia en la medida en que expresa un multiforme sistema de valores: la libertad, la igualdad, la predisposición a la cooperación, la tolerancia y una vocación a la coexistencia pacífica. En síntesis, la cultura laica representa comportamientos de educación política a largo plazo. De acuerdo con Norberto Bobbio, un sistema democrático debe garantizar la existencia de una pluralidad de grupos políticos que participan para tratar de imponer su proyecto -mediante los mecanismos de la ley-al conjunto de la sociedad. Obviamente esta diversidad se ve reflejada en la pluralidad de culturas de las que emanan. El pluralismo reconoce la importancia de los grupos y acentúa el reclamo del relativismo cultural en la redistribución del poder. La sociedad democrática es una sociedad centrífuga que no tiene uno sino varios centros de poder. De aquí el nombre dado por Sartori de poliarquía. ${ }^{14}$ En este sentido se busca una descentralización de la cultura entendida como la revalorización de la periferia respecto del centro, revitalizando al mismo tiempo el papel que tienen los productores y los consumidores de cultura. Recordemos que si bien existe una autonomía relativa, la cultura se ve indirectamente influenciada por la política y en algunos casos históri-

${ }_{13}^{13}$ Robert Dahl, La democrazia e i suoi critici, op. cit., p. 137.

${ }^{14}$ Giovanni Sartori, Teoría de la democracia. El debate contemporáneo, 1989, México, Alianza, p. 217. 


\section{LAURA BACA}

cos aquélla incluso ha tenido un proyecto político determinado. ${ }^{15}$ Lo importante es que esta carga ético-política de la cultura sea proclive a la democracia.

Una cultura laica permite un mayor ejercicio de la crítica y por lo tanto hace posible una mayor transparencia en los actos del poder. Las virtudes del ciudadano laico son el rigor, la imparcialidad, la moderación y la sabiduría, son sobre todo virtudes que se pueden resumir en una: "el no ser prepotente con los demás". ${ }^{16}$ Debemos precisar que la antítesis del espíritu laico es el fanatismo que puede ser definido como la "furia de la destrucción". La cultura laica se contrapone aquellos grupos que pretenden tener un conocimiento superior de lo que es bueno para la comunidad y buscan imponerlo a través de distintos medios. ${ }^{17}$ De lo que se trata es de evitar que la cultura pueda ser instrumentalizada por parte de la política. La cultura laica permite que las ideas de los demás puedan ser discutidas, no rechazadas apriorísticamente, y en el peor de los casos sofocadas. Los portadores de las ideas deben utilizar las armas de la razón y no las razones de las armas y cada uno hacer un esfuerzo para entender las ideas del adversario. Esto aparece como una construcción ideal para nuestras sociedades. Sin embargo sería conveniente aceptar que la cultura laica representa la brújula que nos orienta en el tránsito hacia el siglo XXI, ya que si

${ }^{15}$ En el caso de la lucha contra el fascismo en Italia, la cultura y la política se funden en un mismo proyecto para liberar al país. En este sentido el efecto más visible de la Liberación del fascismo fue: "la renovación de las ideas, lo que dio vida a una de las más fértiles estaciones culturales de la Italia contemporánea". Cfr. Norberto Bobbio, Profilo ideologico del Novecento, 1986, Turín, Einaudi, p. 166.

${ }^{16}$ Norberto Bobbio, Elogio della mitezza, 1994, Milán, Linea d'ombra Edizioni.

${ }^{17}$ Según el pensador italiano Carlo Cattaneo: "el valor de la libertad sintetizaba un preciso programa político de lucha contra cualquier forma de despotismo y el valor de la verdad como un programa cultural de lucha contra cualquier forma de oscurantismo religioso". Cfr. Norberto Bobbio, Una filosofía militante, 1971, Turín, Einaudi, p. 180. 


\section{CULTURA LAICA Y DEMOCRACIA}

con alguna utopía fuese deseable soñar en los tiempos que corren sería, sin duda, aquélla de inspiración kantiana que pugna por la paz perpetua y por la ciudad universal de los ciudadanos. En efecto la civitas maxima no permite la existencia de fronteras y hace posible que los individuos sean al mismo tiempo "más iguales" y más libres. Dentro de esta propuesta es posible observar la presencia de un componente "neoiluminista" que afirma la necesidad de extender la libertad de todos los ciudadanos y de hacer uso público de la propia razón en todos los campos. 